\title{
Experiences Using Airway Pressure Release Ventilation for Pneumonia with Severe Hypercapnia or Postoperative Pulmonary Edema
}

\author{
Kyung Sook Hong', and Young-Joo Lee ${ }^{2}$ \\ ${ }^{1}$ Department of Surgery and Critical Care Medicine, Ewha Womans Univertisty School of Medicine, Seoul; ' 2 Department of Anesthesiology and Critical Care Medicine, Ewha Womans \\ University Medical Center Mokdong Hospital, Seoul, Korea
}

\section{Dear Editor:}

Airway pressure release ventilation (APRV) was introduced as a new method to manage a supportive level of continuous positive airway pressure (CPAP) while simultaneously assisting $\mathrm{CO}_{2}$ elimination [1,2]. APRV maintains CPAP while permitting spontaneous breathing without airway pressure fluctuation [2] and producing alveolar ventilation [3]. It is an established mode of ventilation based on the openlung approach with the following settings: (1) pressure during the in- spiration/ CPAP phase $\left(\mathrm{P}_{\text {high }}\right)$; (2) time during the inspiration/CPAP phase $\left(\mathrm{T}_{\text {high }}\right)$; (3) pressure during the expiration/release phase $\left(\mathrm{P}_{\text {low }}\right) ;(4)$ time during the expiration/ release phase $\left(\mathrm{T}_{\text {low }}\right)$; and (5) percent CPAP (\%CPAP) to reflect the time spent at $\mathrm{P}_{\text {high }}$ relative to the entire breath duration [2] during which positive pressure $\left(\mathrm{P}_{\text {high }}\right)$ was applied for a prolonged time $\left(\mathrm{T}_{\text {high }}\right)$ with a release phase $\left(\mathrm{P}_{\text {low }}\right)$ that is short $\left(\mathrm{T}_{\text {low }}\right)[1,4,5]$. Without self-breathing, the APRV mode is like pressure-controlled inverse ratio ventilation [3].

For patients with acute respiratory distress syndrome (ARDS), the APRV mode has been used as an inverse ratio ventilation with a prolonged inspiratory time and a short expiratory time [3]. Potential benefits of APRV mode include recruitment of lung by rising functional residual capacity and reduction in atelectrauma by decreasing cyclic recruitment and derecruitment to improve ventilation/perfusion (V/Q) matching, while not restricting spontaneous breathing and reducing the sedatives and neuromuscular blockades requirements [4,5]. Because of these advantages, APRV mode is the most used and most studied mode for use in patients with ARDS. However, there have been few clinical trials showing that APRV can improve gas exchange, and it is uncertain whether APRV will improve clinical outcomes.

\author{
Received on November 1, 2016 \\ Revised on December 17, 2016 \\ Accepted on February 13, 2017 \\ Young-Joo Lee \\ Department of Anesthesiology and Critical \\ Care Medicine, Ewha Womans University \\ Medical Center Mokdong Hospital, 1071 \\ Anyangcheon-ro, Yangcheon-gu, Seoul \\ 07985, Korea \\ Tel: +82-2-2650-5366 \\ Fax: +82-2-2650-5906 \\ E-mail: sicuab@hotmail.com
}

*No potential conflict of interest relevant to this article was reported. 
We report our experiences with managing severe hypercapnia or postoperative pulmonary edema using APRV.

\section{Case 1}

A 63-year-old female patient was diagnosed with advanced breast cancer with hepatic metastasis and was treated with palliative chemotherapy consisting of pertuzumab (Perjeta ${ }^{\circledR}$, F. Hoffmann-La Roche, Basel, Switzerland), trastuzumab (Herceptin ${ }^{\circledR}$, F. Hoffmann-La Roche), and docetaxel (Taxotere ${ }^{\circledR}$, Sanofi UK, Dagenham, UK). She was admitted for a third cycle of chemotherapy. However, her chemotherapy schedule did not proceed as planned because she developed pneumonia. In addition to delaying her chemotherapy, she was also transferred to an intensive care unit (ICU) while intubated due to aggravation of the pneumonia on hospital day (HD) \#5. Although the condition of her lungs based on plain radiography of the chest seemed to have recovered with ventilator care, her $\mathrm{pCO}_{2}$ levels on arterial blood gas analysis (ABGA) gradually increased from HD \#16, even with careful ventilator management. On HD \#19, her ABGA demonstrated a $\mathrm{pCO}_{2}$ of $69.2 \mathrm{mmHg}$ (Table 1). Additionally, afterwards, the patient became agitated and exhibited vigorous inspiratory efforts. We increased her respiratory rate from 20 per minute to 24 per minute by securing a sufficient gas-exchange interval and with the use of neuromuscular blockades. However, her $\mathrm{pCO}_{2}$ level declined only to $60.5 \mathrm{mmHg}$. At that time, we decided to apply the APRV mode $\left(\mathrm{P}_{\text {high }} 22 \mathrm{cmH}_{2} \mathrm{O}\right.$, $\mathrm{P}_{\text {low }} 10 \mathrm{cmH}_{2} \mathrm{O}, \mathrm{T}_{\text {high }} 1.2, \mathrm{~T}_{\text {low }} 0.8, \mathrm{FiO}_{2} 0.35$, Table 1) for her, and the follow-up $\mathrm{ABGA}$ results showed a $\mathrm{pCO}_{2}$ of $45.0 \mathrm{mmHg}, \mathrm{pO}_{2}$ of $71.4 \mathrm{mmHg}$ and $\mathrm{SaO}_{2}$ of $93.8 \%$. The next day, her $\mathrm{pCO}_{2}$ level had decreased even more, to 37.8 mmHg (Table 1). On HD \#21, neuromuscular blockades were discontinued and the ventilator mode was changed to the adaptive support ventilation mode (settings: minute volume $100 \%, \mathrm{FiO}_{2} 0.35$, positive end expiratory pressure [PEEP] $10 \mathrm{cmH}_{2} \mathrm{O}$ ). After changing the ventilation mode, ABGA demonstrated very tolerable results (Table 1).

\section{Case 2}

A 63-year-old female patient, who was intubated, was referred to the intensive care unit with a diagnosis of panperitonitis due to colonic perforation after surgery. Her initial postoperative $\mathrm{ABGA}$ results showed a $\mathrm{pH}$ of 7.288, $\mathrm{pCO}_{2}$ of $38.5, \mathrm{pO}_{2}$ of $118, \mathrm{HCO}_{3}^{-}$of 17.8 , and $\mathrm{SaO}_{2}$ of 98.9 with the controlled mandatory ventilation (CMV) mode (settings: tidal volume $470 \mathrm{~mL}$, respiratory rate $10 /$ minute, $\mathrm{FiO}_{2}$ 0.7, PEEP $5 \mathrm{cmH}_{2} \mathrm{O}$ ) (Figure 1A). Initially, septic shock was strongly suspected, therefore the patient was managed with empirical antibiotics (ceftriaxone and metronidazole),

Table 1. Arterial blood gas analysis results using different ventilation modes in case 1

\begin{tabular}{|c|c|c|c|c|}
\hline & $\begin{array}{c}\text { PCV mode } \\
(H D \# 19)\end{array}$ & $\begin{array}{c}\text { APRV mode } \# 1^{\dagger} \\
(H D \# 19)\end{array}$ & $\begin{array}{l}\text { APRV mode \#2 } \\
\quad(H D \# 20)\end{array}$ & $\begin{array}{r}\text { ASV mode } \\
(\text { HD \#21) }\end{array}$ \\
\hline $\mathrm{pH}$ & 7.291 & 7.421 & 7.504 & 7.492 \\
\hline $\mathrm{pCO}_{2}(\mathrm{mmHg})$ & 69.2 & 45.0 & 37.8 & 37.6 \\
\hline $\mathrm{pO}_{2}(\mathrm{mmHg})$ & 89.4 & 71.4 & 73.5 & 85.8 \\
\hline $\mathrm{HCO}_{3}^{-}(\mathrm{mEq} / \mathrm{L})$ & 32.6 & 28.6 & 29.1 & 28.1 \\
\hline $\mathrm{SaO}_{2}(\%)$ & 95.7 & 93.8 & 94.4 & 96.4 \\
\hline $\mathrm{pO}_{2} / \mathrm{FiO}_{2}$ & 255 & 204 & 210 & 245 \\
\hline $\mathrm{FiO}_{2}$ & 0.35 & 0.35 & 0.35 & 0.35 \\
\hline MV (L) & 6.6 & 9.0 & 7.5 & 5.4 \\
\hline
\end{tabular}

PCV: pressure-controlled ventilation; APRV: airway pressure release ventilation; $\mathrm{ASV}$ : adaptive support ventilation; $\mathrm{HD}$ : hospital day; $\mathrm{pCO}_{2}$ : partial pressure of carbon dioxide; $\mathrm{pO}_{2}$ : partial pressure of oxygen; $\mathrm{HCO}_{3}$ : bicarbonate; $\mathrm{SaO}_{2}$ : saturation of oxygen; $\mathrm{FiO}_{2}$ : fraction of inspired oxygen; $\mathrm{MV}$ : minute volume.

"PCV mode: above positive and expiratory pressure (PEEP) $10 \mathrm{cmH}_{2} \mathrm{O}$, respiratory rate 24/minute, $\mathrm{FiO}_{2} \mathrm{0.35}$, PEEP $10 \mathrm{cmH}_{2} \mathrm{O}$.

${ }^{\dagger} \mathrm{APRV}$ mode \#1: $\mathrm{P}_{\text {high }} 22 \mathrm{cmH}_{2} \mathrm{O}, \mathrm{P}_{\text {low }} 10 \mathrm{cmH}_{2} \mathrm{O}, \mathrm{T}_{\text {high }} 1.2, \mathrm{~T}_{\text {low }} 0.8, \mathrm{FiO}_{2} 0.35$.

${ }^{\ddagger} A P R V$ mode \#2: $P_{\text {high }} 22 \mathrm{cmH}_{2} \mathrm{O}, \mathrm{P}_{\text {low }} 10 \mathrm{cmH}_{2} \mathrm{O}, \mathrm{T}_{\text {high }} 1.0, \mathrm{~T}_{\text {low }} 1.0, \mathrm{FiO}_{2} 0.35$.

${ }^{\S}$ ASV mode: minute volume $100 \%, \mathrm{FiO}_{2} 0.35$, PEEP $10 \mathrm{cmH}_{2} \mathrm{O}$. 
vasopressors (norepinephrine and vasopressin) and other supportive treatments, and even continuous renal replacement therapy (CRRT) for severe lactic acidosis (initial lactic acid level of $9.97 \mathrm{mmol} / \mathrm{L}$; maximal lactic acid level of $10.49 \mathrm{mmol} / \mathrm{L}$ ). With intensive treatments, the septic shock improved, such that all vasopressors were tapered and discontinued, and lactic acid levels normalized; however, the pneumonia did not improve (Figure 1B). Postoperative pulmonary edema was combined with the pneumonia, and her oxygen demand was increased $\left(\mathrm{FiO}_{2}\right.$ 0.7) (Table 2). Accordingly, APRV $\left(\mathrm{P}_{\text {high }} 34 \mathrm{cmH}_{2} \mathrm{O}\right.$,
$\mathrm{P}_{\text {low }} 14 \mathrm{cmH}_{2} \mathrm{O}, \mathrm{T}_{\text {high }} 2.0, \mathrm{~T}_{\text {low }} 1.0, \mathrm{FiO}_{2} 0.5$, Table 2) was applied on postoperative day \#6. Pulmonary edema was dramatically improved after just a few hours based on the results of plain chest radiography (Figure 1C, Table 2), and her work of breathing was also decreased. This APRV mode was continued for 7 days, and her follow-up chest radiographic images showed improvement (Figure 1D, Table 2).

Hypercapnia can be avoided by changing ventilator settings, for example, adding pressure support or changing the ratio of inspiratory time to expiratory time (I:E ratio)
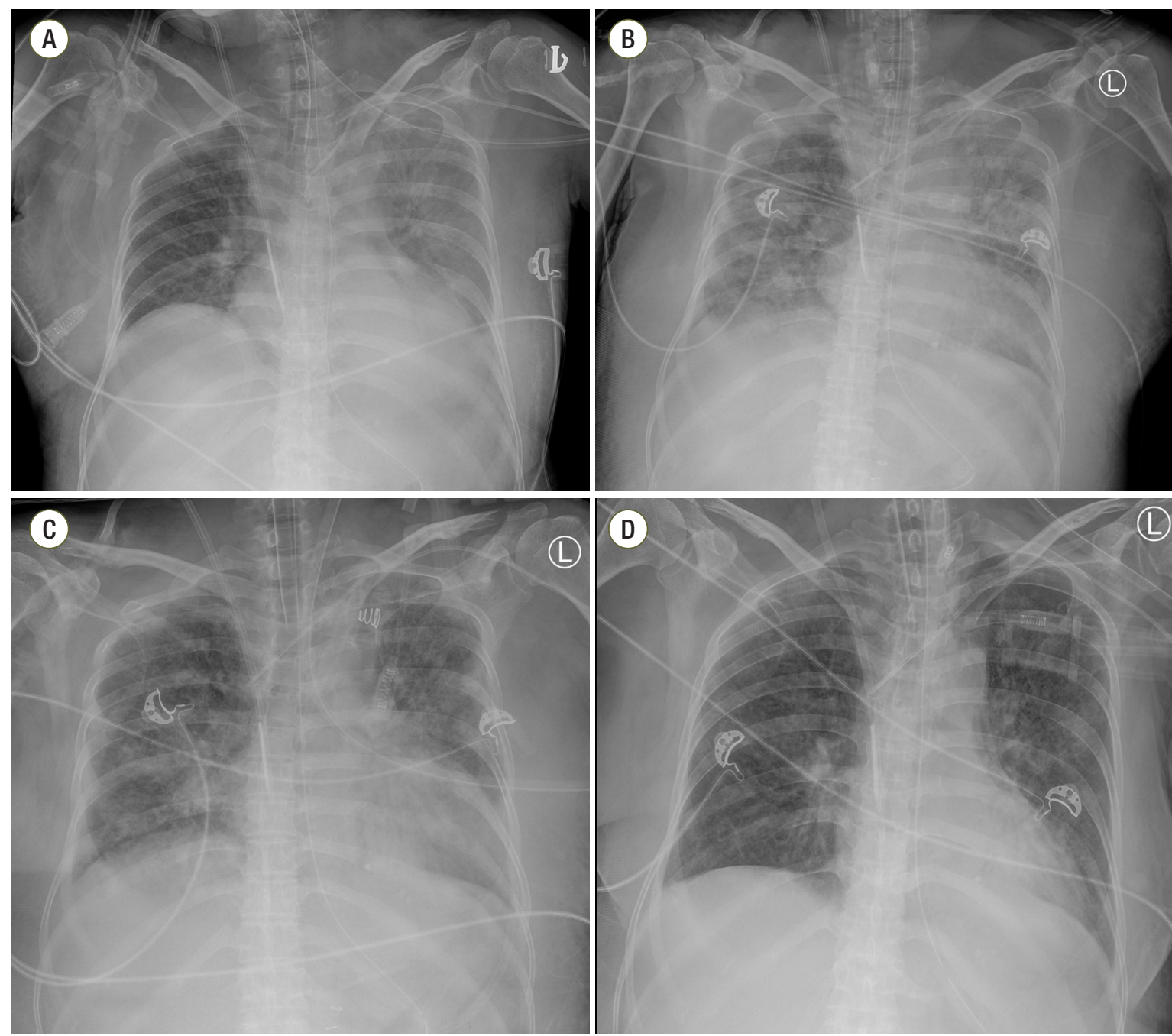

Figure 1. Serial plain radiographic images of the chest using different ventilation modes in case 2. (A) Plain chest radiograph on the day of operation. (B) On postoperative day \#6, the pneumonia combined with postoperative edema was aggravated. (C) Pneumonia combined with edema improved on a follow-up plain radiograph taken just 6 hours after starting APRV. (D) On postoperative day \#12, slightly improvement was noted on the plain chest radiographic image. APRV: airway pressure release ventilation. 
Table 2. Arterial blood gas analysis results using different ventilation modes in case 2

\begin{tabular}{lcccc}
\hline & $\begin{array}{c}\text { SIMV-PC mode } \\
\text { (POD \#6) }\end{array}$ & $\begin{array}{c}\text { APRV mode }^{\dagger} \\
\text { (POD \#6) }\end{array}$ & $\begin{array}{c}\text { APRV mode } \\
\text { (POD \#7) }\end{array}$ & $\begin{array}{c}\text { SIMV-PC mode }^{\S} \\
\text { (POD \#12) }\end{array}$ \\
\hline $\mathrm{pH}$ & 7.444 & 7.436 & 7.511 & 7.526 \\
$\mathrm{pCO}_{2}(\mathrm{mmHg})$ & 36.0 & 35.4 & 32.0 & 41.0 \\
$\mathrm{pO}_{2}(\mathrm{mmHg})$ & 76.6 & 77.5 & 179.4 & 119.8 \\
$\mathrm{HCO}_{3}(\mathrm{mEq} / \mathrm{L})$ & 24.1 & 23.3 & 25.0 & 33.2 \\
$\mathrm{SaO}_{2}(\%)$ & 94.7 & 95.1 & 99.1 & 98.3 \\
$\mathrm{pO}_{2} / \mathrm{FiO}_{2}$ & 109 & 155 & 449 & 300 \\
$\mathrm{FiO}_{2}$ & 0.7 & 0.5 & 0.4 & 0.4 \\
$\mathrm{MV}(\mathrm{L})$ & 9.1 & 9.0 & 9.4 & 8.9 \\
\hline
\end{tabular}

SIMV-PC: pressure controlled synchronized intermittent mandatory ventilation; $\mathrm{APRV}$ : airway pressure release ventilation; $\mathrm{pCO}_{2}$ : partial pressure of carbon dioxide; $\mathrm{pO}_{2}$ : partial pressure of oxygen; $\mathrm{HCO}_{3}$ : bicarbonate; $\mathrm{SaO}_{2}$ : saturation of oxygen; $\mathrm{FiO}_{2}$ : fraction of inspired oxygen; $\mathrm{MV}$ : minute volume.

${ }^{*}$ SIMV-PC mode: above positive and expiratory pressure (PEEP) $15 \mathrm{cmH}_{2} \mathrm{O}$, respiratory rate 15/minute, $\mathrm{FiO}_{2}$ 0.7, PEEP $10 \mathrm{cmH}_{2} \mathrm{O}$, controlled pressure $18 \mathrm{cmH} \mathrm{H}_{2} \mathrm{O}$.

${ }^{\dagger}$ APRV mode \#1: $\mathrm{P}_{\text {high }} 34 \mathrm{cmH}_{2} \mathrm{O}, \mathrm{P}_{\text {low }} 14 \mathrm{cmH}_{2} \mathrm{O}, \mathrm{T}_{\text {high }} 2.0, \mathrm{~T}_{\text {low }} 1.0, \mathrm{FiO}_{2} 0.5$.

${ }^{\ddagger} A P R V$ mode \#2: $\mathrm{P}_{\text {high }} 34 \mathrm{cmH}_{2} \mathrm{O}, \mathrm{P}_{\text {low }} 14 \mathrm{cmH}_{2} \mathrm{O}, \mathrm{T}_{\text {high }} 2.0, \mathrm{~T}_{\text {low }} 1.0, \mathrm{FiO}_{2} 0.4$

${ }^{\S}$ SIMV-PC mode: above PEEP $15 \mathrm{cmH}_{2} \mathrm{O}$, respiratory rate 15/minute, $\mathrm{FiO}_{2}$ 0.4, PEEP $10 \mathrm{cmH}_{2} \mathrm{O}$, controlled pressure $15 \mathrm{cmH}_{2} \mathrm{O}$.

in conventional ventilation modes, such as CMV [3,4]. In our first case, however, the patient did not improve even using neuromuscular blockades. The APRV settings were determined to facilitate $\mathrm{CO}_{2}$ removal with an inverse I:E ratio and $\mathrm{P}_{\text {low }}$ was also kept at $10 \mathrm{mmHg}$ to avoid patient lung collapse during $T_{\text {low }}$, just like in case 1 .

In APRV, the lungs are ventilated with a lower airway pressure close to the lower inflection point, which reduces the over expansion of the alveoli. It promotes gas exchange and improves oxygenation by better lung recruitment [3].

Additionally, in our second case of postoperative pulmonary edema, APRV may have been the ideal ventilator mode. There has been no previous well-designed study on APRV for postoperative pulmonary edema, although some individual cases have been reported [6].

Increased mean alveolar pressure with short release time $\left(\mathrm{T}_{\text {low }}\right)$ promotes the recuitment of collapsed lung while preventing over-distention of ventilated alveoli. APRV aids in pulmonary dysfunction management by maximizing alveolar recruitment while limiting the transalveolar pressure gradient, thereby reducing the risk of barotrauma [6]. Additionally, in an animal experiment, it has been shown that APRV reduces lung water [7].

APRV increases the intrathoracic pressure to reduce the venous return and, therefore, to lower the blood pressure in some cases. In addition, it is difficult to apply APRV to the patients with obstructive airway disease such as asthma. The use of APRV, however, resulted in improved ventilation and oxygenation and increased mean alveolar pressure. Additionally, many studies have reported significant benefits of APRV on cardiopulmonary variables [2]. Moreover, in this ventilation mode, the stability of the lungs can be controlled independently from breathing to breathing, which is not possible with other modes of ventilation [2]. Hence, we suggest that APRV may be very helpful for patients with severe hypercapnia or hypoxemia related to postoperative pulmonary edema in ICU.

\section{ORCID}

Kyung Sook Hong http://orcid.org/0000-0002-8022-5693

Young-Joo Lee http://orcid.org/0000-0002-6512-3891

\section{References}

1. Stock MC, Downs JB, Frolicher DA. Airway pressure release ventilation. Crit Care Med 1987; 15: 462-6. 
2. Jain SV, Kollisch-Singule M, Sadowitz B, Dombert L, Satalin J, Andrews P, et al. The 30-year evolution of airway pressure release ventilation (APRV). Intensive Care Med Exp 2016; 4: 11.

3. Arshad Z, Prakash R, Aggarwal S, Yadav S. Ventilating patient with refractory hypercarbia: use of APRV mode. J Clin Diagn Res 2016; 10: UD01-2.

4. Modrykamien A, Chatburn RL, Ashton RW. Airway pressure release ventilation: an alternative mode of mechanical ventilation in acute respiratory distress syndrome. Cleve Clin J Med 2011; 78: 101-10.

5. Lim J, Litton E, Robinson H, Das Gupta M. Characteristics and outcomes of patients treated with airway pressure release ventilation for acute respiratory dis- tress syndrome: a retrospective observational study. J Crit Care 2016; 34: 154-9.

6. Morimoto Y, Sugimoto T, Arase H, Haba F. Successful management using airway pressure release ventilation for severe postoperative pulmonary edema. Int J Surg Case Rep 2016; 27: 93-5.

7. Matsuzawa Y, Nakazawa K, Yamamura A, Akashi T, Kitagaki K, Eishi Y, et al. Airway pressure release ventilation reduces the increase in bronchoalveolar lavage fluid high-mobility group box-1 levels and lung water in experimental acute respiratory distress syndrome induced by lung lavage. Eur J Anaesthesiol 2010; 27: 726-33. 